This item was submitted to Loughborough's Research Repository by the author.

Items in Figshare are protected by copyright, with all rights reserved, unless otherwise indicated.

\title{
Blue-emitting butterfly-shaped 1,3,5,9-tetraarylpyrenes: synthesis, crystal structures, and photophysical properties
}

PLEASE CITE THE PUBLISHED VERSION

http://dx.doi.org/10.1021/ol4002653

\section{PUBLISHER}

(c) American Chemical Society

\section{VERSION}

AM (Accepted Manuscript)

\section{PUBLISHER STATEMENT}

This work is made available according to the conditions of the Creative Commons Attribution-NonCommercialNoDerivatives 4.0 International (CC BY-NC-ND 4.0) licence. Full details of this licence are available at: https://creativecommons.org/licenses/by-nc-nd/4.0/

\section{LICENCE}

CC BY-NC-ND 4.0

\section{REPOSITORY RECORD}

Feng, Xing, Jian-Yong Hu, Fumitaka Iwanaga, Nobuyuki Seto, Carl Redshaw, Mark R.J. Elsegood, and Takehiko Yamato. 2019. "Blue-emitting Butterfly-shaped 1,3,5,9-tetraarylpyrenes: Synthesis, Crystal Structures, and Photophysical Properties". figshare. https://hdl.handle.net/2134/18267. 


\title{
Blue emitting Butterfly-Shaped 1,3,5,9-Tetraarylpyrenes: Synthesis, Structures, and Physical Properties
}

\author{
Xing Feng, ${ }^{a}$ Jian-Yong $\mathrm{Hu},{ }^{a}$ Fumitaka Iwanaga, ${ }^{a}$ Nobuyuki Seto, ${ }^{a}$ \\ Carl Redshaw, ${ }^{b}$ Mark R. J. Elsegood, ${ }^{c}$ and Takehiko Yamato ${ }^{a}$ \\ ${ }^{a}$ Department of Applied Chemistry, Faculty of Science and Engineering, Saga University, Honjo-machi \\ 1, Saga 840-8502 Japan, ${ }^{b}$ Department of Chemistry, The University of Hull, HU6 7RX, UK and \\ ${ }^{c}$ Chemistry Department, Loughborough University, Loughborough, LE11 3TU, UK. \\ yamatot@ cc.saga-u.ac.jp
}

Received Date (will be automatically inserted after manuscript is accepted)
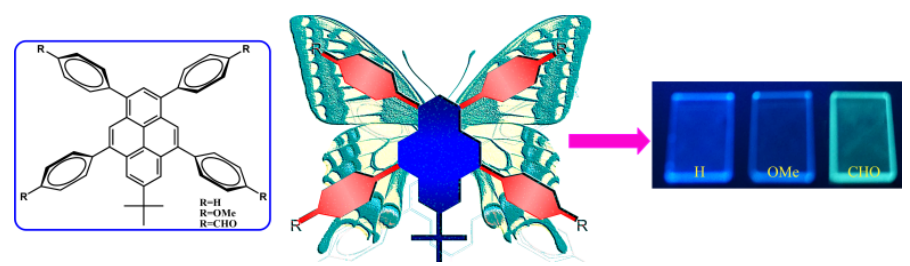

Novel butterfly-shaped, highly fluorescent stable monomers of the type 7-tert-butyl-1,3,5,9-tetrakisarylpyrene were synthesized by the Suzuki-Miyaura coupling reaction of the new bromopyrene derivative 7-tert-butyl-1,3, 5,9-tetrabromopyrene with the corresponding arylboronic acids.

The design and synthesis of efficient electroluminescent materials based on polyaromatic hydrocarbons (PAH) has been under investigation for well over a decade. ${ }^{1}$ Pyrene and its derivatives ${ }^{2}$ are important members of the polyaromatic hydrocarbon family (PAHs) that have exhibited several advantages: (1) solution processable, (2) good thermal stability, (3) enhanced charge carrier mobility, and (4) intense luminescence efficiency. Indeed, polyaromatics have been employed in organic light-emitting diodes (OLEDs) ${ }^{2,3}$ as well as in other optoelectronic devices, ${ }^{4}$ and as fluorescence probes. ${ }^{5}$ However, the use of pyrene as an efficient emitting material in OLED applications has been somewhat limited, primarily because the planar structure has a tendency to form $\pi$-aggregates/excimers thereby quenching the fluorescence in concentrated solution or in the solid state. To suppress the aggregation, many research groups have focused on exploring the availability of methods for the functionalization of the pyrene core. In general, the 1-, 3-, 6-, and 8-positions of pyrene preferentially undergo electrophilic aromatic substitution $\left(\mathrm{S}_{\mathrm{E}} \mathrm{Ar}\right)$ reactions. Thus, various pyrene derivatives (see SI) can be easily accessed depending on the experimental conditions. ${ }^{2,6}$ On the other hand, the 4-,
5-, 9- and 10- positions of the parent pyrene are susceptible to bromination in the presence of iron powder, in the presence of sterically bulky tert-butyl groups located at the 2- and 7-positions as positional protective groups. $^{7}$ Even on extending the reaction time, pentabromide pyrene derivative would be obtained. ${ }^{8}$ Besides electrophilic substitution of pyrene, Harris showed an efficient, one-step synthetic approach to catalyze the oxidation of the K-region of pyrene using ruthenium chloride. ${ }^{11}$ Müllen et. al. ${ }^{10}$ have developed an asymmetric functionalization method to direct bromine atoms to the K-region without the need for tert-butyl groups. Additionally, in our laboratory, we also reported the selective formation of the 5-mono- and 5,9-di-substitution products from 7-tert-butyl-1,3-dimethylpyrene by formylation and acetylation depending on the type of Lewis acid catalyst deployed. ${ }^{12}$ More recently, the 1 - and 3- positions of pyrene were brominated using 2-tert-butylpyrene; the tert-butyl group on the pyrene ring protects the ring from electrophilic attack at the 6,8-positions. ${ }^{9}$

Based on the previously mentioned research, we decided to exploit a new intermediate in order to develop a series of pyrene related materials for further 
applications. Our initial efforts attempted to synthesize 7-tert-butyl-1,3,4,5,9,10-hexabromo-pyrene (3) using iron powder to catalyze its formation from 2-tert-butylpyrene in different solvents, however efforts using $\mathrm{CH}_{2} \mathrm{Cl}_{2}$, nitrobenzene, and benzene, all failed. A bromo atom substituted at the 1- and 3-positions of pyrene would sterically hinder the 4- and 10- positions, thereby enabling regioselective substitution at the 5- and 9positions. Since the 7-position of the pyrene core has been protected, four bromines atoms can be introduced at the 1-, 3-, 5-, 9- positions by electrophilic bromination of 2-tert-butylpyrene in the presence of iron powder. The 7-tert-butyl-1,3,5,9-tetrabromopyrene (2) was prepared and purified successfully in excellent yield. To the best of our knowledge, this is the first example of a method to halogenate pyrene not only in the activated sites but also in the K-region. The intermediate 2 has two advantages: ${ }^{2 a}$ (1) the active sites at the 1- and 3- positions could give C-functionalized pyrene by Suzuki/Sonogashira coupling reactions to avoid aggregation; (2) the K-region (5-, 9positions) affords a strategy to extended conjugated systems to larger PAHs by cyclization reaction.

Scheme 2. Synthetic route to compound 4, 5

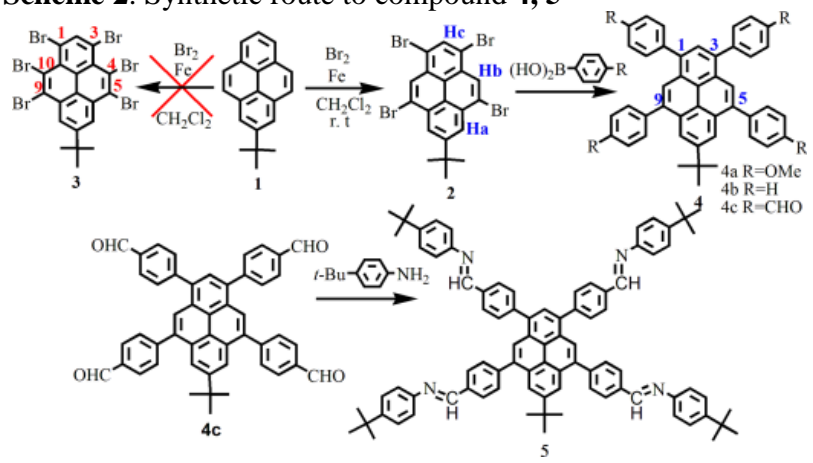

The synthesis of target compound $\mathbf{4}$ is depicted in Scheme 2. Pyrene was first mono-tert-butylated to afford the 2-tert-butylpyrene (1), which was then treated with $\mathrm{Br}_{2}$ (4 equivalents) in $\mathrm{CH}_{2} \mathrm{Cl}_{2}$ at room temperature in the presence of iron powder, yielding the desired 7-tert-butyl1,3,5,9-tetrkisbromo-pyrene 2 in high yield (83.5 \%). Compound $\mathbf{2}$ is a white solid powder, which is slightly soluble in common organic solvents, such as $\mathrm{CH}_{2} \mathrm{Cl}_{2}$ and $\mathrm{CHCl}_{3}$. The ${ }^{1} \mathrm{H}$ NMR spectrum showed three singlets between $\delta$ 8.47-8.80 ppm region ( $\mathrm{Ha}, \mathrm{Hb}, \mathrm{Hc}$ ), and a singlet for the pyrene protons in the ratio 2:2:1, consistent with the symmetrically substituted structure of 2 .

In the present study, we report the synthesis, structure, optical and electrochemical characterization of a series of butterfly-shaped pyrene-core derivatives of the type 7-tert-butyl-1,3,5,9-tetraarylpyrene (4), which utilized the key starting material $\mathbf{2}$ by reacting in a Suzuki cross-coupling reaction with the corresponding arylboronic acids under Pd-catalyzed conditions in the presence of an excess amount of toluene (65-71 \% isolated yields, see SI). The molecular structure of the compounds of type 4 were characterized by their ${ }^{1} \mathrm{H} /{ }^{13} \mathrm{C}$ NMR spectra, single crystal X-ray diffraction, FT-IR spectroscopy, mass spectroscopy, and by elemental analysis. As a comparison, the aromatic aldehyde $4 \mathrm{c}$ was condensed with 4-tert-butylaniline to afford the Schiff base 5, and 1,3,6,8-tetrakis(4-methoxyphenyl)pyrene (6) was synthesized according to the modified literature procedure. $^{13}$ The 7-tert-butyl-1,3,5,9-tetraarylpyrenes $\mathbf{4}$ were soluble in common organic solvents such as toluene, $\mathrm{CH}_{2} \mathrm{Cl}_{2}, \quad \mathrm{CHCl}_{3}$, THF, acetonitrile, and $\mathrm{N}, \mathrm{N}$-dimethyl-formamide, and exhibited excellent thermal stability under air $/ \mathrm{N}_{2}$. The key thermal data for the pyrene derivatives $\mathbf{4}$ are summarized in Table 1 .

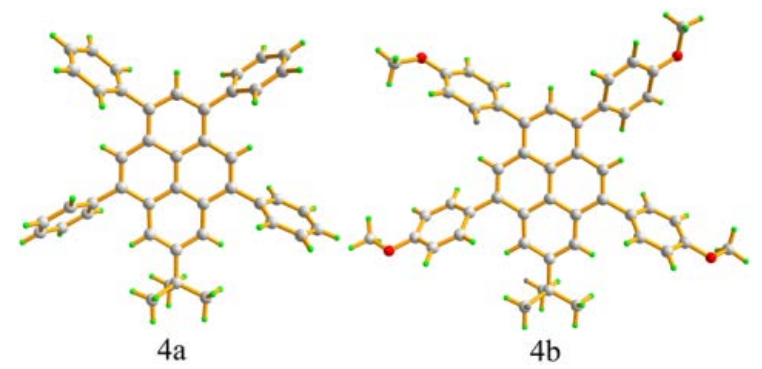

Figure 1. X-ray structure of compounds $4 a$ and $4 b$

Single crystals of 4a (CCDC 917256), 4b (CCDC 917257) and 6 (CCDC 915429) were grown from a mixture of $\mathrm{CH}_{2} \mathrm{Cl}_{2}$ and $\mathrm{MeOH}$ and were investigated by $\mathrm{X}$-ray crystallography to establish the structure. All crystal structures were found to belong to the monoclinic crystal system with space group $P 2_{1} / c$ for $\mathbf{4 a}$ and $\mathbf{6}$, and $P 2_{1} / n$ for $\mathbf{4 b}$. As shown in Figure 1 , these terminal moieties adopt a reasonably twisted conformation with a substantial dihedral angle relative to the pyrene ring (46.2-68.0 $0^{\circ}$, and torsion angles of $49.4-70.5^{\circ}$ between the pyrene and phenyl rings, whilst for the pyrene and methoxylphenyl rings, the torsion angles were $48.1-56.2^{\circ}$. In the presence of a tert-butyl group at the 7-position of pyrene, the four terminal moieties twist with reasonable dihedral angles relative to the pyrene cores. This conformation effectively prevents $\pi-\pi$ stacking and releases the steric interactions in the solid state. Only $\mathrm{C}-\mathrm{H} \cdots \pi$ interactions were observed and impact on molecular geometries as well as prevent the excimer formation in the solid state. ${ }^{16}$ The packing of molecules of 4a and $\mathbf{4 b}$ reveal the 2D self-assembled planar solid-state structure (see SI). The comparison compound $\mathbf{6}$ exhibited a sandwich-like 3D structure self-assembled in solid state via $\mathrm{C}-\mathrm{H} \cdots \pi$ bond interactions overlapping the porous two-dimensional networks. A chloroform molecule was encapsuled in the molecular channel by a hydrogen

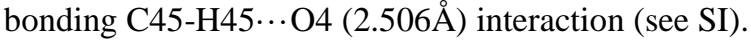

The UV/vis absorption and fluorescence spectra of $\mathbf{4 , 5}$ and $\mathbf{6}$ were investigated in dilute dichloromethane and in a thin film (see Figure 2). The four compounds exhibit two prominent absorption bands between 298-308 nm and $373-391 \mathrm{~nm}$, and the optical absorption spectrum of 
Table 1. The photophysical and electrochemical properties of compounds $\mathbf{4 , 5}$ and $\mathbf{6}$.

\begin{tabular}{|c|c|c|c|c|c|c|c|c|c|c|c|}
\hline \multirow{2}{*}{$\begin{array}{c}\begin{array}{c}\text { Titled } \\
\text { molecular }\end{array} \\
4 a\end{array}$} & \multicolumn{2}{|c|}{$\underline{\lambda_{\max }} \underset{\text { solns }^{a} / \text { films }^{b}}{\operatorname{abs}(\mathrm{nm})}$} & \multicolumn{2}{|c|}{$\underline{\lambda_{\max }} \frac{\text { PL (nm) }}{\text { solns }^{a} / \text { films }^{b}}$} & \multirow{2}{*}{$\begin{array}{c}\boldsymbol{\Phi}_{f}^{c} \\
\text { solns / thin films } \\
0.92 / 0.75\end{array}$} & \multirow{2}{*}{$\begin{array}{c}\begin{array}{c}\text { LUMO } \\
(\mathrm{eV})\end{array} \\
-1.58\end{array}$} & \multirow{2}{*}{$\begin{array}{c}\begin{array}{c}\text { HUMO } \\
(\mathbf{e V})\end{array} \\
-5.01\end{array}$} & \multirow{2}{*}{$\begin{array}{c}\text { HOMO-LUMO } \\
\begin{array}{c}\Delta \mathbf{E}(\mathrm{eV}) \\
3.43\end{array}\end{array}$} & \multirow{2}{*}{$\begin{array}{c}T_{g}^{d} \\
93\end{array}$} & \multirow{2}{*}{$\begin{array}{c}T_{m}^{d} \\
\left({ }^{\circ} \mathbf{C}\right) \\
292\end{array}$} & \multirow{2}{*}{$\begin{array}{c}\begin{array}{c}\boldsymbol{T}_{d}{ }^{e} \\
\left({ }^{\circ} \mathrm{C}\right)\end{array} \\
350.1\end{array}$} \\
\hline & 373 & 380 & 412 & 410 & & & & & & & \\
\hline $4 b$ & 379 & 369 & 421 & 443 & $0.90 / 0.72$ & -1.36 & -4.76 & 3.40 & 94 & 276 & 410.0 \\
\hline $4 c$ & 386 & 400 & 469 & 471 & $0.56 / 0.48$ & -2.45 & -5.66 & 3.21 & 94 & 301.5 & 328.8 \\
\hline 5 & 355 & & 467 & -- & -- & -2.12 & -5.25 & 3.13 & -- & 265.6 & 430.2 \\
\hline 6 & 391 & 405 & 434 & 488 & $0.94 /-$ & -1.47 & -4.71 & 3.24 & -- & 270.5 & -- \\
\hline
\end{tabular}

${ }^{a}$ Maximum absorption wavelength measured in dichloromethane at room temperature. ${ }^{b}$ Measured in thin neat films. ${ }^{c}$ Measured in dichloromethane and in neat thin films, respectively. ${ }^{d}$ Melting temperature $\left(T_{\mathrm{m}}\right)$ obtained from differential scanning calorimetry (DSC) measurement. ${ }^{e}$ Decomposition temperature $\left(T_{\mathrm{d}}\right)$ obtained from thermogravimetric analysis (TGA).

4c was very broad and less well resolved in the range from 330 to $420 \mathrm{~nm}$. For substituents bearing electronic donating or accepting groups at the para-position of the phenyl ring, the compounds have a slight red shift and followed the order $\mathbf{6}(\mathrm{OMe})>\mathbf{4} \mathbf{c}(\mathrm{CHO})>\mathbf{4 b}(\mathrm{OMe})>\mathbf{4 a}(\mathrm{H})$; similar influences on the photophysical properties of compounds have been noted previously. ${ }^{9 b, 14}$ Compounds 4 and $\mathbf{6}$ exhibited absorption $\lambda_{\max }$ values that were significantly red-shifted in comparison to the parent 2-tert-butylpyrene (338 nm). For the Schiff base 5, the bulky blocking group (the 4-tert-butylphenylamine moiety) was introduced at the para-position of the benzene rings in order to expand the $\pi$-conjugation of the butterfly-shaped system. The broad absorption spectrum had $\lambda_{\max }$ at $355 \mathrm{~nm}$, which indicated that the delocalization of the $\pi$ electrons was extended over a large area of the molecule.

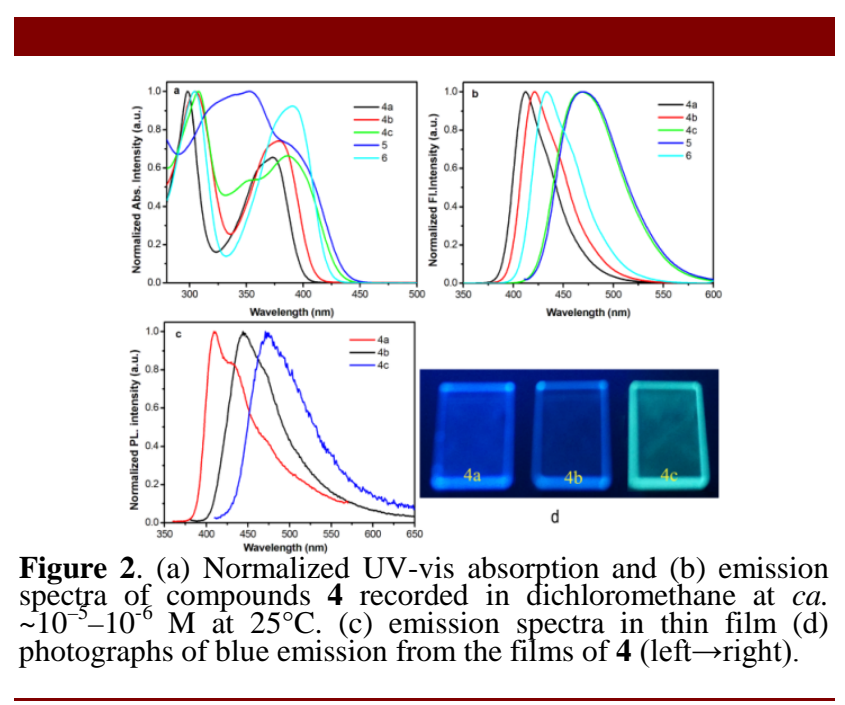

For thin film absorption, compounds of type 4 have slightly broader spectra with a red shift (5-14 nm) in comparison to that observed in solution (Table 1). This was ascribed to aggregate formation in the solid-state. In the case of compound $\mathbf{6}$ however, an unusual zigzag type absorption spectrum curve was observed in the solid-state, and the maximum absorption band at $\lambda 391 \mathrm{~nm}$ suggested that the 1,3,6,8-tetrakis(4-methoxy-phenyl)pyrene (6) possessed extensive intermolecular interactions as a film (see SI). Figures $2 \mathrm{~b}$ and 2c reveal that the butterfly-shaped compounds 4 emit very bright, sharp and deep blue fluorescence, both in solution and in the solid-state. The emission maxima at $412 \mathrm{~nm}$ for $\mathbf{4 a}$ and $421 \mathrm{~nm}$ for $\mathbf{4 b}$ reveal a smaller red shift than compound $\mathbf{6}$ $\left(\lambda_{\text {max }}=434 \mathrm{~nm}\right)$. For $4 \mathbf{c}$, the presence of the CHO moiety, caused a significant red-shift and a broadened emission maximum $\left(\lambda_{\max }\right)$ at $469 \mathrm{~nm}$ in dilute dichloromethane. Interestingly, when the extended terminal 4-tert-butylphenyliminophenyl groups were replaced by the carbaldehyde group in $\mathbf{4 c}$, a similar emission maximum at $469 \mathrm{~nm}$ with weak fluoresence intensity occurred. Nevertheless, no excimer emission was observed in this butterfly-shaped tetraarylpyrene system.

The photoluminescence spectrum of $\mathbf{4}$ as a thin-solid film presents a prominent maximum emission in the blue region (410 $\mathrm{nm}$ for $\mathbf{4 a}, 443 \mathrm{~nm}$ for $\mathbf{4 b}$ and $471 \mathrm{~nm}$ for $\mathbf{4 c}$ ). For $\mathbf{4 a}$, the wavelength of the emission maximum ( $\lambda_{\max }$ ) shows a slight hypsochromic shift in the solid state with respect to the dichloromethane solution spectrum (413 $\mathrm{nm})$. This difference may be due to the different dielectric constant in the solid state versus dilute solutions. ${ }^{15}$ Compound $\mathbf{4 b}$ displayed a slight red-shift (approx. 22 $\mathrm{nm}$ ) compared to spectra recorded as dilute solutions (Table 1), thought to be due to aggregation. For $\mathbf{4 c}$, there was a slight red-shift (increased by $2 \mathrm{~nm}$ ) in solution versus thin film. Compounds 4 also exhibited very high quantum yields $\left(\boldsymbol{\Phi}_{f}^{c}\right)$ of ca. $0.92,0.90$ and 0.56 in solution and ca. $0.75,0.72$ and 0.48 in the solid state, respectively. There is thus potential for such systems as efficient pure-blue emitters. However, the fluorescence emission spectrum of $\mathbf{6}$ obtained in the solid state showed two emission bands at $488 \mathrm{~nm}$ and $564 \mathrm{~nm}$. The longer wavelength band in the solid state is assigned to the emission of the excimer. which suggested compound $\mathbf{6}$ has strong aggregation in the solid state due to the absence of a tert-butyl group to suppress the intermolecular interactions in the molecular structure.

To further understand the electronic structures and optical properties of these novel butterfly-shaped pyrene derivatives 4, 5 and 6, DFT (B3LYP/6-31G*) calculations were performed. The frontier orbitals for $\mathbf{4}$ are shown in Figure 3, Table 1 and SI, the HOMO is delocalized over the entire pyrene framework for $\mathbf{4 , 5}$ and $\mathbf{6}$, whereas the aryl substituent group or extended chain have limited 
contributions to this system. Similarly, the LUMOs of $\mathbf{4 a}$ and $\mathbf{4 b}$ were also delocalized over the whole pyrene unit. However, it is remarkable that the LUMO of $4 \mathbf{c}$ spreads over the entire pyrene framework, including the 4-formylphenyl unit. It is interesting to note that although enlarging the $\pi$ conjugation by introducing the $\mathrm{C}=\mathrm{N}$ bond in $\mathbf{5}$, the terminal phenylimino groups do not contribute to the construction of the LUMO in $\mathbf{5}$.

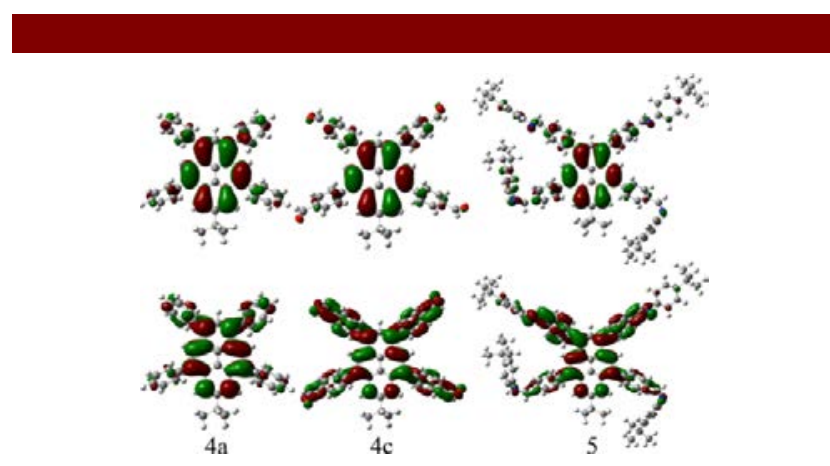

Figure 3. Computed molecular orbital plots (B3LYP/6-31G*) of selected compounds $\mathbf{4}$ and $\mathbf{5}$. The lower plots represent the HOMOs, and the upper plots represent the LUMOs.

The electrochemical properties of $\mathbf{4}$ were investigated by cyclic voltammetry (CV). All compounds showed oxidation waves located at $1.48 \mathrm{~V}$ for $4 \mathrm{a} ; 1.35 \mathrm{~V}$ and 1.73 $\mathrm{V}$ for $\mathbf{4 b}$, and $1.75 \mathrm{~V}$ for $\mathbf{4 c}$, (versus ferrocenium/ ferrocene $\left.\left(\mathrm{Fc}^{+} / \mathrm{Fc}\right)\right)$. All compounds display oxidation wave originating from the conjugation system of pyrene. The HOMO energy levels were calculated to be $-5.49 \mathrm{eV}$ for $\mathbf{4 a},-5.36 \mathrm{eV}$ for $\mathbf{4 b}$ and $-5.73 \mathrm{eV}$ for $\mathbf{4 c}$, respectively, from the onset of the first oxidation wave. The Energy gap (Eg) was estimated from UV-vis absorption $(3.11 \mathrm{eV}$ for $\mathbf{4 a}, 3.01 \mathrm{eV}$ for $\mathbf{4 b}$ and $2.88 \mathrm{eV}$ for $\mathbf{4 c}$ ). The experimental data was found to closely correspond to the theoretically calculated data (See SI). The slight difference owing to the theoretical calculation being performed for the gas phase. The high reversibility of their redox processes demonstrated that the butterfly-shaped pyrene derivatives were stable, and suggested that the current molecular design may be suitable for applications in OLED-like optoelectronic devices. In particular, the low LUMO of 4c can be used for hole-transportation in organic materials.

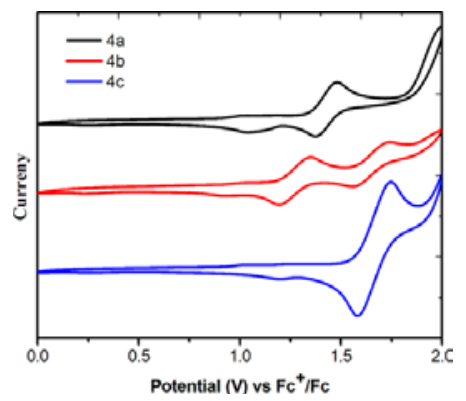

Figure 7. Cyclic voltammograms recorded for the compounds 4
In conclusion, we have developed a new synthetic method for the construction of 7-tert-butyl-1,3,5,9tetrabromopyrene (2), which is a key bromopyrene intermediate for designing and synthesizing efficient blue emitters. The tert-butyl group and the 4-fold functionalization efficiently suppressed molecular aggregation both in solution (UV-vis and fluorescence) and in the solid state (photoluminescence and crystal packing). This work provides a promising strategy to halogenate both at the active sites and in the K-region. Our current butterfly-shaped molecular design may provide an efficient strategy to achieve solid-state blue emitting materials for realizing full-color display of OLEDs. Further investigation of their applications in organic electroluminescent devices is in progress in our laboratory.

Acknowledgment This work was performed under the Cooperative Research Program of "Network Joint Research Center for Materials and Devices (Institute for Materials Chemistry and Engineering, Kyushu University)". We would like to thank the OTEC at Saga University and the International Collaborative Project Fund of Guizhou province at Guizhou University for financial support. We also would like to thank the EPSRC (overseas travel grant to C.R.) and The Royal Society for financial support.

Supporting Information Available Synthetic procedures and characterization data; this material is available free of charge via the Internet at http://pubs.acs.org.

(1) (a) Havey, R. G. Polycyclic Aromatic Hydrocarbons; Wiley-VCH: New York, 1997. (b) Schmidt-Mende, L.; Fechtenkötter, A.; Müllen, K.; Moons, E.; Friend, R. H.; MacKenzie, J. D. Science, 2001, 293, 1119-1122. (c) Richter, M. M., Chem. Rev., 2004, 104, 3003-3036.

(2) Figueira-Duarte, T. M.; Müllen, K. Chem. Rev., 2011, 111, 7260-7314.

(3) (a) Lo, M. Y.; Zhen, C-G.; Lauters, M.; Jabbour, G. E.; and Sellinger, Alan. J. Am. Chem. Soc. 2007, 129, 5808-5809.

(4) (a) Ashizawa, M.; Yamada, K.; Fukaya, A.; Kato, Reizo.; Hara, K.; and Takeya, J. Chem. Mater., 2008, 20, 4883-4890. (b) Wen, Y-G.; Liu, Y-Q.; Guo, Y-L.; Yu, G.; and Hu, W-P. Chem. Rev., 2011, 111, 3358-3406.

(5) (a) Goedeweeck, R.; Vanderauweraer, M.; Deschryver, F. C. J. Am. Chem. Soc. 1985, 107, 2334-2341. (b) Ni, X-L.; Zeng, X.; Redshaw, C.; and Yamato, T. J. Org. Chem., 2011, 76, 5696-5702 (c) Ahmed, N.; Shirinfar, B.; Geronimo, I.; and Kim, K. S. Org. Lett., 2011, 13, 5476-5479. (d) Lewis, F. D.; Zhang, Y. F.; Letsinger, R. L. J. Am. Chem. Soc. 1997, 119, 5451-5452.

(6) (a) Bernhardt, S.; Kastler, M.; Enkelmann, V.; Baumgarten, M.; Müllen, K. Chem. Eur. J. 2006, 12, 6117-6128. (b) Vollmann, H.; Becker, H.; Corell, M.; Streeck, H. Justus Liebigs Ann. Chem., 1937, 531, 1-159.

(7) Yamato, T.; Fujimoto, M.; Miyazawa, A.; Matsuo, K. J. Chem. Soc. Perkin Trans. 1, 1997, 1201-1207.

(8) Hu, J-Y.; Ni, X-L.; Feng, X. Era, M.; Elsegood, M. R. J.; Teatd, S. J.; Yamato, T. Org. Biomol. Chem., 2012, 10, 2255-2262.

(9) (a) Figueira-Duarte, T. M.; Simon, S. C.; Wagner, M.; Druzhinin, S. I.; Zachariasse, K. A.; Müllen, K. Angew. Chem. Int. Ed. 2008, 47, 10175-10178. (b) Feng, X.; Hu, J-Y.; Yi, L.; Seto, N.; Tao, Z.; Redshaw, C.; Elsegood, M. R. J.; Yamato, T. Chem. Asian J. 2012, DOI: 10.1002/asia.201200530

(10) Zöphel, L.; Beckmann, D.; Enkelmann, V.; Chercka, D.; Rieger, R. Müllen, K. Chem. Commun., 2011, 47, 6960-6962.

(11) Hu, J.; Zhang, D.; Harris, F. W., J. Org. Chem., 2005, 70, 707-708.

(12) Hu, J-Y.; Paudel, A. Yamato, T. J. Chem. Res. 2008, 308-311.

(13) Halleux, V. de.; Callbert, J.-P.; Brocorens, P.; Cornil, J.; Declercq, J-P.; Brédas, J-L.; Geerts, Y. Adv. Funct. Mater. 2004, 14, 649-659.

(14) Hu, J.-Y.; Era, M.; Elsegood, M. R. J.; Yamato, T. Eur. J. Org. Chem. 2010, 72-79.

(15) Tyagi, P.; Venkateswararao, A. and Thomas, K. R. J. J. Org. Chem. 2011, 76, 4571-4581.

(16) (a) Wurthner, F.; Thalacker, C.; Diele, S.; Tschierske, C. Chem.sEur. J. 2001, 7, 2245-2253.(b) Jenekhe, S. A.; Osaheni, J. A. Science, 1994, 265, 765-768. 